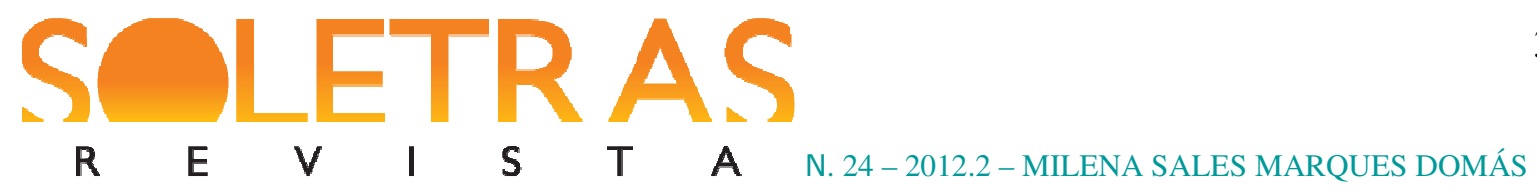

\title{
Universitários vão à escola: relatos de sujeitos envolvidos na "construção de pontes" entre a Faculdade de Formação de Professores da UERJ e o Colégio Estadual Capitão Oswaldo Ornellas
}

\author{
Milena Salles Marques Domás ${ }^{1}$
}

\begin{abstract}
Resumo: Este trabalho tem como objetivo refletir, de maneira específica, sobre as mudanças ocorridas no Colégio Estadual Capitão Oswaldo Ornellas, em São Gonçalo, a partir da atuação de bolsistas do Programa Institucional de Bolsa de Iniciação à Docência (PIBID) e das atividades desenvolvidas pelos monitores do projeto "Mais Educação" - estudantes de graduação da Faculdade de Formação de Professores (FFP) da UERJ. Para isso, coletamos relatos de sujeitos envolvidos na ligação entre a FFP e a unidade escolar em questão. $\mathrm{O}$ artigo dialoga, principalmente, com as contribuições de Prado \& Soligo (2010); tais autores nos ajudam a pensar a importância de relatar a experiência, em especial de indivíduos que estão passando por processo de formação. Os sujeitos cujas experiências serão relatadas no presente texto são: (1) as professoras/supervisoras do PIBID; (2) um bolsista do mesmo projeto; (3) uma monitora do Projeto "Mais Educação"; (4) um aluno da escola; (5) a diretora geral da unidade escolar. Além disso, procuramos imprimir nosso próprio relato. Acreditamos que a relevância do trabalho consiste em avaliar quais são os benefícios gerados para alunos, professores e futuros professores quando pontes são construídas entre a Faculdade e a escola.
\end{abstract}

Palavras-chave: Universidade. Escola. Relatos de experiência. Formação.

\section{Introdução}

Neste artigo, pretendemos pensar as relações entre a Faculdade de Formação de Professores e a escola. De maneira mais específica, queremos refletir sobre as mudanças que a presença de bolsistas do Programa Institucional de Bolsa de Iniciação à Docência (PIBID); monitores do Projeto "Mais Educação" - estudantes de graduação da Faculdade de Formação de Professores (FFP) da UERJ - têm provocado no Colégio Estadual Capitão Oswaldo Ornellas, no qual atuam, lecionando Língua Portuguesa e Literatura.

Para isso, coletamos relatos de um aluno da escola, das supervisoras (que também são professoras da unidade escolar), de um bolsista do projeto PIBID, de uma monitora do Projeto "Mais Educação" e da diretora geral do Colégio Estadual Capitão Oswaldo Ornellas. Além disso, buscamos imprimir as nossas impressões enquanto ex-estagiária e bolsista de Iniciação

\footnotetext{
${ }^{1}$ Graduada em Letras na Faculdade de Formação de Professores da UERJ. Atualmente está concluindo o Mestrado em Educação: Processos Formativos e Desigualdades Sociais, pela mesma instituição. Pesquisa, principalmente, os temas: práticas de linguagem e novas tecnologias da informação e da comunicação.
} 


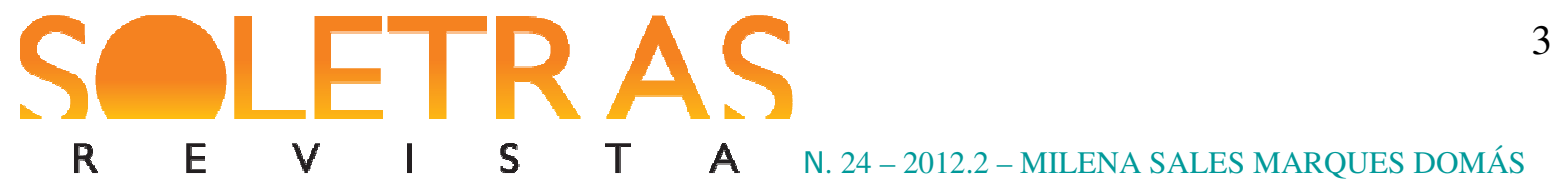

à Docência e, já formada e após ter prestado concurso, enquanto professora de Língua Portuguesa e Literatura da referida escola.

Esses relatos e impressões tratam da experiência dos sujeitos da unidade escolar com relação às mudanças ocorridas no dia a dia, na dinâmica da escola e no comportamento dos alunos por causa da presença de universitários na escola, através do PIBID e de atividades desenvolvidas por monitores do Projeto "Mais Educação". O registro dos relatos visa à compreensão sobre o que essas mudanças significam para os indivíduos que, de alguma forma, estão envolvidos nessa relação entre a FFP e o Colégio Estadual Capitão Oswaldo Ornellas.

É importante ressaltar que a Faculdade de Formação de Professores está localizada próximo ao Colégio Estadual Capitão Oswaldo Ornellas - esta, no bairro Porto Novo e aquela, no Paraíso - hoje Patronato -, bairros vizinhos da cidade de São Gonçalo. Essa proximidade é uma das causas para a constante procura de estudantes de graduação da FFP pela escola, em busca de realizarem seus estágios supervisionados ou atividades relacionadas a projetos de pesquisa da Faculdade. Todos os alunos da FFP que procuram a escola são sempre muito bem recebidos e acolhidos pela direção e por professores do colégio.

Nossa primeira percepção das pontes construídas entre a FFP e o Colégio Estadual Capitão Oswaldo Ornellas se deu durante o período de graduação, através de atuação como estagiária e também como bolsista de Iniciação à Docência ${ }^{2}$ na referida escola. Neste período, já era possível perceber que havia resultados muito positivos da presença de universitários junto aos alunos da educação básica. Hoje, como professora e pesquisadora atuante na mesma unidade escolar, é possível identificar como a relação entre estagiários, bolsistas e monitores da FFP com alunos e professores do Colégio Capitão Oswaldo Ornellas é capaz de trazer modificações na dinâmica da escola e até mesmo naquilo que os sujeitos nela inseridos esperam no que se refere às atividades ali realizadas. Como já dissemos, buscamos imprimir, no presente trabalho, algumas dessas mudanças decorridas da relação entre Faculdade e escola.

Consideramos importante trazer algumas informações sobre os dois projetos já referidos aqui, o PIBID e o "Mais Educação". Segundo informações da Capes, o PIBID, Programa Institucional de Bolsa de Iniciação à Docência, busca aperfeiçoar e valorizar a formação de professores para a educação básica. Participam do programa alunos de

\footnotetext{
${ }^{2}$ Fui bolsista de Iniciação à Docência, do projeto "Literatura e jornal: quem quer integrar este caso?", coordenado pela Professora Maria Cristina Ribas (FFP/UERJ).
} 


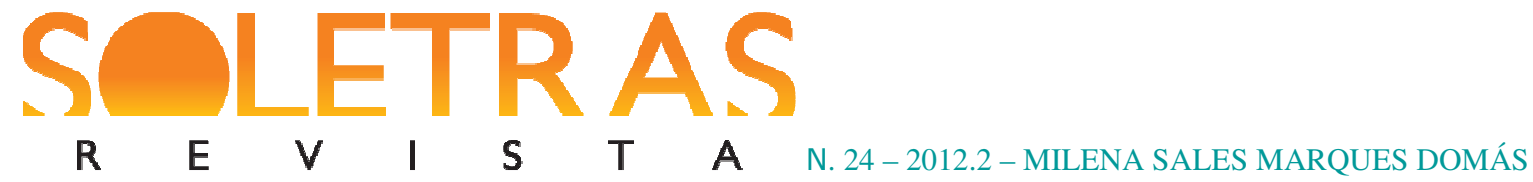

licenciatura que fazem parte de projetos de Iniciação à Docência desenvolvidos por Instituições de Ensino Superior. Esses alunos passam a desenvolver atividades pedagógicas em uma escola pública, sob orientação de um professor de licenciatura e um professor da escola. No Colégio Estadual Capitão Oswaldo Ornellas, o projeto é desenvolvido por graduandos dos cursos de Letras da FFP, sob a orientação de uma docente do Departamento de Letras da Faculdade ${ }^{3}$ e supervisão de duas professoras da escola; o foco das atividades realizadas está voltado para a leitura e produção textual com base em gêneros textuais populares. Já o projeto "Mais Educação", de acordo com o portal do MEC, procura aumentar a oferta educativa em escolas públicas através de atividades optativas com acompanhamento pedagógico e visa ainda à melhora do ambiente escolar através dessas atividades. Na escola pública em questão, o "Mais Educação" oferece aulas de Língua Portuguesa, Matemática, Informática, Canto, Teatro e Dança, lecionadas principalmente por estudantes e ex-estudantes de diferentes cursos da FFP.

Chamamos para o diálogo no artigo as contribuições de Prado \& Soligo (2010), os quais nos ajudarão a pensar a importância de relatar a experiência, em especial de indivíduos que estão passando por processo de formação. Os sujeitos cujas experiências serão relatadas no presente texto são: (1) as professoras/supervisoras do PIBID; (2) um bolsista do mesmo projeto; (3) uma monitora do Projeto "Mais Educação"; (4) um aluno da escola; (5) a diretora. Além disso, trouxemos nosso próprio relato, escrito com base em nossas impressões desde o período da graduação, quando atuamos como bolsista e estagiária. Ademais, atentamos para algumas contribuições de autores como Freire (2003) e Nóvoa (2003).

\section{Por que escolhemos registrar relatos (de experiência)?}

Como explicamos resumidamente nas considerações iniciais deste artigo, queremos refletir sobre a relação entre a Faculdade de Formação de Professores da UERJ e o Colégio Estadual Capitão Oswaldo Ornellas e, para isso, recolhemos relatos de experiência de sujeitos envolvidos em projetos e atividades realizadas pela Faculdade na/com a escola. Fizemos essa escolha, primeiramente por acreditar que os relatos podem revelar as mudanças ocorridas na escola em função da presença de sujeitos da FFP, a partir da visão daqueles que, de alguma maneira, são afetados por essas modificações. Além disso, compreendemos que os relatos

\footnotetext{
${ }^{3}$ Professora Maria Isaura Rodrigues Pinto, do departamento de Letras - DEL - da Faculdade de Formação de professores da UERJ, em São Gonçalo.
} 


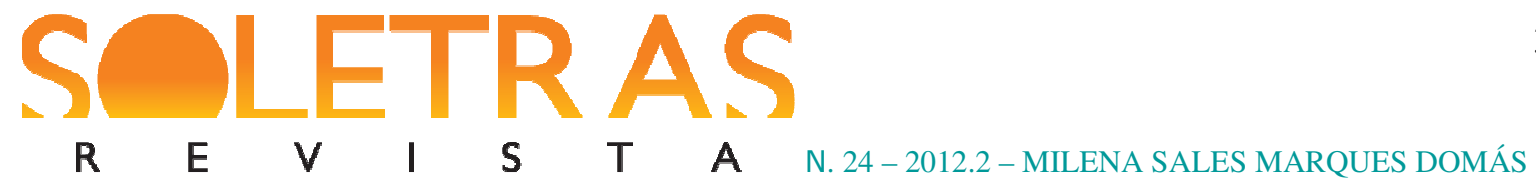

podem não só mostrar que mudanças a escola tem vivido, mas também a experiência dos sujeitos e o que essas transformações significam para a direção da escola, bolsistas, monitores, professores e alunos.

Prado \& Soligo (2010) nos ajudam a pensar em outro aspecto da relevância dos relatos: a contribuição na formação de professores. Antes de desenvolvermos esta questão é preciso esclarecer que os relatos que registramos neste artigo não são apenas de professores ou estudantes de licenciatura, mas também de um aluno da escola. Contudo, acreditamos que os autores dos relatos, assim como todos nós, estão em constante processo de formação e por isso, o lado positivo da prática da escrita de relatos vale também para os alunos.

Prado \& Soligo (2010) esclarecem que cada vez mais os profissionais da educação têm sido reconhecidos como protagonistas de mudanças que contribuem para um "novo tempo no Magistério" (2010, p.1). Como afirmam, há uma perspectiva da formação de profissionais reflexivos e foi nesse contexto que a escrita de professores passou a ser valorizada:

\begin{abstract}
Afinal, se é necessária a reflexão sobre a prática profissional e se escrever favorece o pensamento reflexivo, a conclusão acaba por ser inevitável: a produção de textos escritos é uma ferramenta valiosa na formação de todos [...]. Quando os educadores tornam públicos os seus textos, todos ganhamos. (PRADO; SOLIGO, 2010, p. 1).
\end{abstract}

De acordo com os autores, até algum tempo atrás, os textos produzidos por profissionais da educação funcionavam apenas como respostas a exigências institucionais e tinham, muitas vezes, sua autoria omitida, ou seja, essa escrita não era valorizada como produção legítima, digna de publicação e capaz de contribuir na formação e no dia a dia de outros profissionais da área. Neste trabalho, ressaltamos, buscamos legitimar as vozes dos sujeitos através do registro de seus relatos como produções capazes de levar à compreensão sobre os resultados da presença de universitários na escola. Procuramos ajudar esses indivíduos a enfrentar "o desafio de assumir a palavra e tornar públicas as suas opiniões, as suas inquietações, as suas experiências (...)” (PRADO; SOLIGO, 2010, p. 2).

É necessário ainda pensar nos relatos como narrativas, afinal, seus autores narraram um pouco de sua experiência, de sua opinião, de suas impressões e sentimentos acerca da relação entre a FFP e o Colégio Estadual Capitão Oswaldo Ornellas. Conforme explicam Prado \& Soligo (2010), 


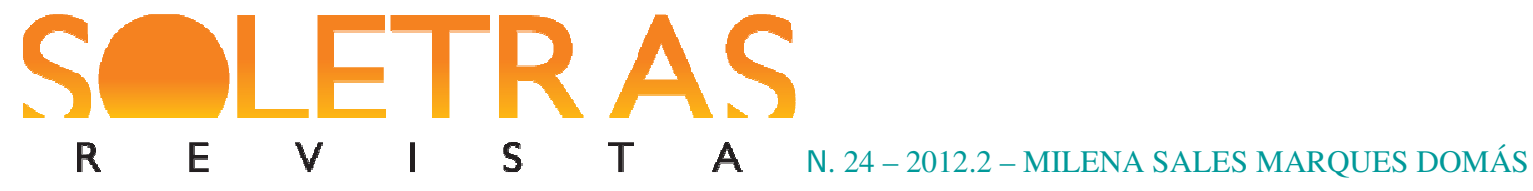

A palavra narrar vem do verbo latino narrare, que significa expor, contar, relatar. E se aproxima do que os gregos antigos clamavam de épikos poema longo que conta uma história e serve para ser recitado. Narrar tem, portanto, essa característica intrínseca: pressupõe o outro. Ser contada ou ser lida: é esse o destino de toda história. E se 'as coisas estão prenhes da palavra', como preferia Bakhtin, ao narrar falamos de coisas ordinárias e extraordinárias... e até repletas de mistérios - que vão sendo reveladas ou remodeladas no ato da escuta ou na suposta solidão da leitura. (PRADO; SOLIGO, 2010, p. 3). (Grifos nossos).

Como destacamos acima, a narrativa pressupõe o outro. Nossa intenção ao abordar os autores dos relatos foi fazê-los perceber que suas vozes seriam ouvidas, suas produções seriam lidas, suas experiências valorizadas. Prado \& Soligo (2010) lembram-nos que "a narrativa é um excelente veículo para tornar público o que fazemos” (2010, p. 7), isso significa que podemos ver no ato de narrar um caminho para dar ao outro "a compreensão daquilo que estamos fazendo e do que pensamos sobre o que fazemos" (2010, p. 7).

A seguir, apresentamos os relatos (ou trechos de relatos) das duas professoras que supervisionam o PIBID, de um bolsista do mesmo programa, de uma monitora do projeto "Mais Educação", de um aluno do Colégio Estadual Capitão Oswaldo Ornellas, da diretora geral da escola, além do nosso próprio relato, escrito com base em nossas impressões desde o período da graduação, quando atuamos como bolsista e estagiária.

\section{Registro de relatos de experiência de "construtores de pontes" entre a FFP e o Colégio Estadual Capitão Oswaldo Ornellas}

Reunimos aqui o registro de relatos de professores, um bolsista, uma monitora, um aluno, a diretora da escola, sujeitos que de alguma forma estão envolvidos com atividades que possuem vínculos com a Faculdade, desenvolvidas na escola. Por isso, chamamos estes sujeitos de "construtores de pontes", pois através de sua participação nas atividades que têm sido realizadas, permitem relações mais estreitas entre a Faculdade de Formação de Professores da UERJ e o Colégio Estadual Capitão Oswaldo Ornellas.

De acordo com Prado \& Soligo (2010, p.7), "alguns profissionais sentem uma certa dificuldade em relação a como começar a escrever e a como encaminhar o texto" na hora de redigir um relato, um memorial ou uma autobiografia. Os autores sugerem ter um tema central, pré-determinado, a fim de facilitar a produção do texto. Procuramos motivar os sujeitos e ajudá-los a encontrar uma boa maneira de dizer aquilo que realmente fosse relevante para eles. 


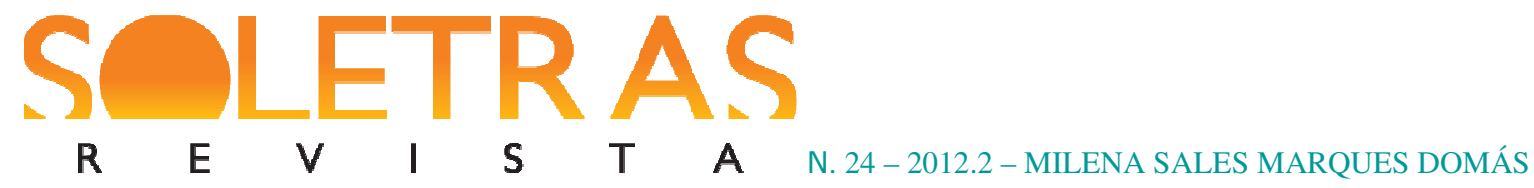

Seguindo a orientação de Prado \& Soligo (2010), antes de pedir que produzissem os relatos, conversamos com os sujeitos e lançamos alguns questionamentos que acreditávamos serem capazes de auxiliá-los no momento de tecer seus textos; na verdade, esperávamos que seus relatos respondessem a essas perguntas, que são as seguintes: $\mathrm{O}$ que a presença da FFP significa para a escola? Que mudanças você consegue perceber no cotidiano da escola e no comportamento dos alunos com a inserção de indivíduos da Faculdade na unidade escolar? Como é a recepção dos sujeitos da escola ao(s) projeto(s)? O que o projeto PIBID/ "Mais Educação" tem significado para sua formação (enquanto professor em formação contínua, futuro professor ou aluno)?

Após cada relato, buscaremos apontar como a opinião de seus autores é capaz de ajudar na reflexão sobre a influência mútua entre Faculdade e Escola. Os primeiros relatos que reunimos são os das duas professoras de Língua Portuguesa da escola Capitão Oswaldo Ornellas que supervisionam os bolsistas do PIBID, Maria José e Dayse.

É importante ressaltar que os nomes dos autores dos relatos são verdadeiros, pois entendemos com Prado e Soligo (2010) que a escrita desses sujeitos deve ser valorizada como produção legítima, por isso sua autoria não poderia ser omitida.

\section{Relatos}

\subsection{Relato de Maria José}

A presença da Universidade na escola é sinônimo de inovações, novas práticas. E a importância do PIBID está justamente em trazer aulas mais atrativas para os alunos, aulas inovadoras. O projeto trouxe para a escola novas maneiras de trabalhar com os gêneros textuais, em especial os populares: contos, cordéis, poemas...

Percebo que com as atividades do projeto, os alunos conseguem expressar de forma criativa o conteúdo proposto, por exemplo, nas aulas sobre cordel, eles foram muito espontâneos em suas produções, de maneira que antes não demonstravam ser. Apesar de algumas turmas terem ficado um pouco apáticas diante das tarefas e da exposição das aulas, a maior parte dos alunos despertou muito bem para os temas trabalhados. Um outro exemplo foi o Festival de Poesias que deixou os estudantes bem empolgados.

Na escola, ninguém atrapalhou a inserção do projeto e ainda hoje os professores apoiam o desenvolvimento das atividades; muitas vezes, até cedem algum tempo de suas 


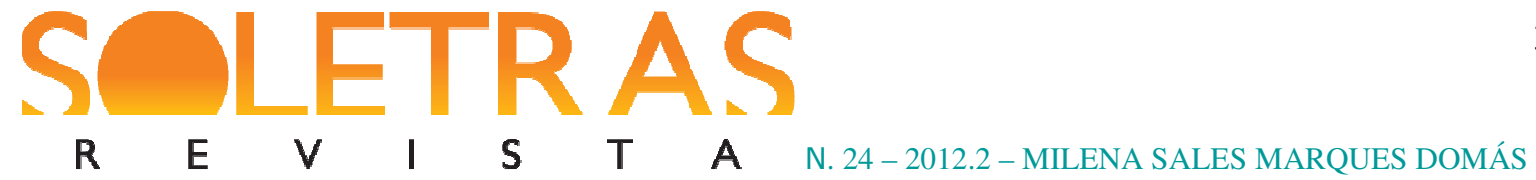

aulas para os bolsistas. O trabalho tem surtido efeito para alunos, professores e futuros professores.

Para mim a experiência também é ótima, o novo é sempre muito bom. Já tenho trinta anos de Magistério, mas ainda aprendo com as ideias, sugestões que são trazidas pelos bolsistas e pela própria proposta do projeto. Além do mais é muito bom conviver com jovens que estão se formando na universidade, preparando-se para serem professores.

O relato da professora Maria José, nos possibilita identificar algumas mudanças ocorridas na escola após a inserção do PIBID, dentre elas, a espontaneidade de alunos no momento de participar das atividades, o que, segundo a docente não acontecia antes. Destacamos ainda o fato de Maria José ter revelado em sua narrativa a maneira como esse movimento entre PIBID e escola a afetam: apesar de ser professora há trinta anos, ela sente, ao lado dos bolsistas, que ainda pode aprender. Essa afirmação nos permite confirmar que a escrita de relatos de experiência pode contribuir para a formação de professores (PRADO \& SOLIGO, 2010), já que o ato de produção da narrativa pode ter auxiliado a docente a perceber a contribuição da relação faculdade-escola para sua profissão.

\subsection{Relato de Dayse}

O que vejo de mais importante é a parceria que se construiu entre a faculdade e a escola. Todos os que trabalham ou estudam na escola, mas principalmente os alunos, acolheram muito bem o projeto e depois da entrada do PIBID na escola, o cotidiano escolar melhorou muito, a dinâmica é outra. Um dos motivos para essa transformação é a forma como os bolsistas trabalham os conteúdos, com uma nova abordagem e usando vários recursos que muitos professores da escola não utilizam, como o Datashow.

Com a realização do Festival de Poesias, vimos o desenvolvimento dos alunos na escrita, na interpretação de textos. Até mesmo com relação a trabalhos em grupo, percebemos que os alunos passaram a ter mais afinidade entre si, mais facilidade para ouvir e aceitar a opinião do outro na hora de realizar uma tarefa.

Acredito que a formação dos bolsistas recebe muitas contribuições, penso que depois da vivência no PIBID, estarão mais preparados quando entrarem em uma sala de aula como professores efetivos. 


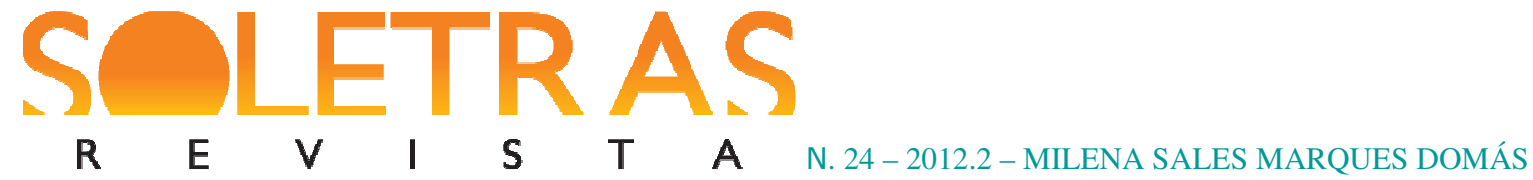

A narrativa de Dayse nos permite observar, principalmente, a influência do PIBID na vida de alunos e bolsistas. A autora não fala de nenhuma mudança ocorrida consigo mesma, mas demonstra ser uma profissional reflexiva (PRADO; SOLIGO, 2010), pois através da atuação do projeto na escola, do qual ela participa ativamente, consegue ver muitas transformações nas atitudes dos alunos da escola diante das atividades propostas. Além disso, vislumbra o amadurecimento dos bolsistas enquanto futuros professores.

Além dos relatos das duas professoras que supervisionam diretamente o trabalho do PIBID, coletamos o relato de Eduardo, um estudante do curso de Letras (Português/ Literaturas) da FFP e bolsista do PIBID desde a introdução do projeto no Colégio Estadual Capitão Oswaldo Ornellas.

\subsection{Relato de Eduardo}

Para a escola, a proposta do PIBID é a de ter aulas diferenciadas daquelas do “currículo normal”, o que acaba sendo interessante para os alunos. Nós sempre tentamos usar todos os dispositivos disponíveis para atrair os estudantes.

Pelas culminâncias já realizadas, percebemos que o projeto avança e a escola está ganhando, há um estímulo para os alunos estarem em contato com a Língua Portuguesa.

Do início do projeto até aqui já tivemos rejeição e aprovação por parte dos estudantes e ainda há alguns que não participam das atividades. Mas a escola nos recebeu de braços abertos, a escola se abriu e nos permite implementar o projeto; nunca encontramos barreiras para realizar as atividades. Os alunos são supercarinhosos, a grande maioria quer contribuir e me sinto bem acolhido por eles.

Para a minha formação como docente há muitas contribuições. Foi a partir de minha participação no PIBID que tive meu primeiro contato com uma escola sem estar na posição de aluno; esse contato, a experiência efetiva com uma metodologia de ensino, o contato com as novas tecnologias, a promoção e a formulação do projeto me fizeram ter certeza da minha vocação como professor, certeza de que é realmente isso que eu quero. Creio que isso irá refletir quando eu estiver com um diploma na mão. Tudo está contribuindo para minha formação, pois não tive só a experiência da pesquisa na teoria, mas também na prática.

O relato de Eduardo parte de outro olhar, o olhar de um bolsista que chegou há pouco tempo na escola, mas já consegue identificar a importância do contato entre os universitários e 


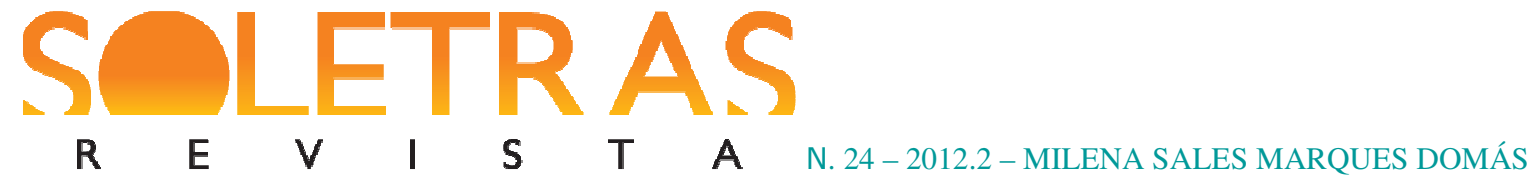

o ambiente escolar. O estudante aborda em sua narrativa as contribuições do PIBID para a escola e também as modificações que a atuação no projeto tem gerado para sua formação. Acreditamos que o relato de Eduardo é capaz de estimular outros universitários a ingressarem em projetos de pesquisa e vivenciarem experiências parecidas com as dele.

A seguir apresentamos trechos do relato de Camila, que se formou no curso de Pedagogia pela Faculdade de Formação de Professores da UERJ, atuou como bolsista no período da graduação e há dois anos é monitora do projeto "Mais Educação" no Colégio Estadual Capitão Oswaldo Ornellas, lecionando dança.

\subsection{Relato de Camila}

Vou falar daquilo que conheço mais de perto, das mudanças e contribuições que percebo através das aulas de dança. Fazer pedagogia foi o que mudou a minha visão do que é ensinar dança. Além disso, dar aulas de dança em uma escola pública faz diferença, é uma experiência diferente.

Na minha percepção, as aulas de dança oferecidas pelo "Mais Educação" ajudam na socialização entre os alunos, no desenvolvimento deles, na sua postura, na disciplina. Professores de dança têm fama de durões, mas eu procuro trabalhar de outra forma, tenho uma didática, o meu olhar é outro. Aprender dança deixa de ser a prioridade nas minhas aulas, eu olho para a necessidade os alunos e tento perceber como minhas aulas podem ajudá-los. [...]

O comportamento de muitos alunos mudou, o Igor (nome fictício), por exemplo, era um aluno muito travado, que não sabia muito bem como lidar com os colegas, mas ele se transformou em uma pessoa comprometida com o projeto, com a escola; tornou-se alguém mais coerente na hora de agir. [...]

Então, acredito que a dança ajuda na formação dos alunos como cidadãos; de alguma forma mostra ao aluno sua importância. Tudo isso é um ganho para a escola que só pude perceber por causa de minha formação na faculdade.

A narrativa de Camila nos chama atenção, principalmente, porque a monitora enfrentou "o desafio de assumir a palavra e tornar públicas as suas opiniões, (...) as suas experiências (...)" (PRADO; SOLIGO, 2010, p.2). Ela relata não só a maneira como costuma trabalhar, mas também os benefícios que as aulas de dança podem gerar. Percebemos ainda 


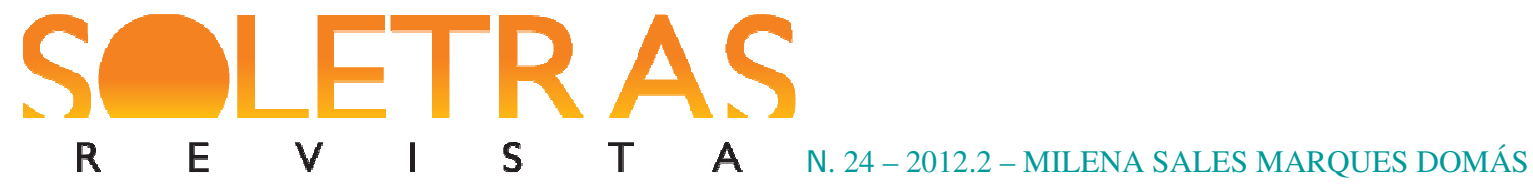

uma preocupação por parte da monitora em fazer com que suas aulas contribuam para a vida dos alunos.

Trazemos ainda o relato do aluno Luan, estudante do $8^{\circ}$ ano do Colégio Estadual Capitão Oswaldo Ornellas. Ele está envolvido com o projeto "Mais Educação", fazendo aulas de Teatro, Informática, Português e Matemática; além disso, participa das atividades propostas pelos bolsistas do PIBID. O aluno foi autor de um poema durante o Festival de Poesias realizado pelo PIBID na escola e um dos diretores no Festival de Contos.

\subsection{Relato de Luan}

$\mathrm{Na}$ minha opinião os projetos que estão na escola contribuem muito para o comportamento dos alunos, que melhorou bastante. Os projetos também exploram a criatividade dos alunos.

As pessoas da escola acham os projetos bons porque sem eles (os projetos) não haveria atividades extracurriculares. Os alunos, principalmente, gostam do "Mais Educação" e do PIBID porque além de fazerem atividades que não faziam antes na escola, têm a oportunidade de conhecer novos amigos, inclusive de outros turnos.

Depois que comecei a participar dos projetos, meu desempenho como aluno melhorou, eles ajudam na minha formação e aprendo além do que normalmente aprendo na escola.

Luan fala da sua posição enquanto aluno da escola; destacamos no relato construído por ele, a percepção do estudante com relação à contribuição dos projetos em sua formação e na formação de seus colegas. Como ele mesmo indica, seu desempenho melhorou e, ao lado de outros alunos, faz o que antes não fazia na escola.

Também registramos trechos do relato da diretora geral da escola, Denise, que está na direção da escola há sete anos e viu a inserção do projeto "Mais Educação" em 2010 e a entrada do PIBID em 2011. Além da presença dos projetos na unidade escolar, a diretora recebe, a cada ano, vários estagiários de licenciatura, principalmente estudantes da Faculdade de Formação de Professores da UERJ, que, como já dissemos, localiza-se próximo à escola. 


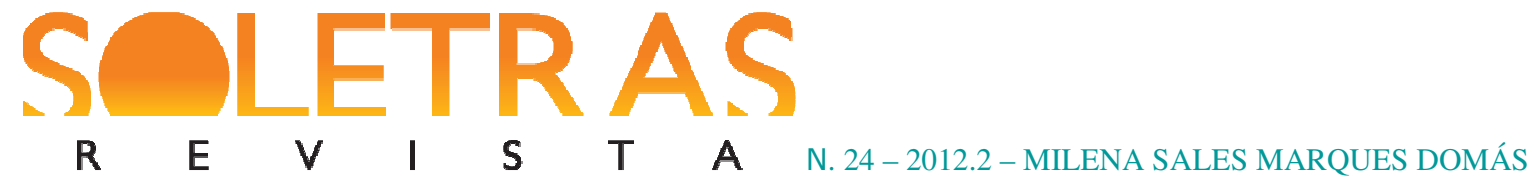

\subsection{Relato de Denise}

Penso que é muito importante manter a parceria entre a faculdade e a escola. A própria proximidade entre as duas instituições já é uma oportunidade para nossos alunos. Os estudantes da escola estão em contato constante com universitários e podem, assim, sentiremse estimulados a ingressar em uma universidade, futuramente. Por isso acredito que o laço precisa permanecer.

Sempre preciso preencher documentos como exigência da Secretaria de Educação e um deles me questiona sobre o que é forte e o que é fraco na escola e a presença da FFP em nossa U.E. sempre aparece como força em minha resposta.

Aqui no Oswaldo, os estudantes da FFP sentem que não há rejeição por parte de funcionários, professores ou alunos; os estagiários, monitores e bolsistas sentem-se acolhidos, o que nem sempre percebem quando procuram realizar as atividades da faculdade em outras escolas, conforme eles mesmos nos contam. Esse acolhimento acontece porque todos do corpo docente e discente de nossa escola compreendem que a presença dos universitários só contribui. [...]

O "Mais Educação" tem o objetivo de trazer os alunos para dentro da escola, fazendo-os permanecer nela quase em tempo integral; esse objetivo tem sido alcançado e temos evitado que alunos estejam em outros locais que poderiam significar algum risco para eles. As oficinas funcionam como reforço para os estudantes e também os ajudam na concentração, na disciplina, na assiduidade.

O PIBID trabalha com as turmas de maneira diferenciada. Os bolsistas desenvolvem o conteúdo de Português com aulas atrativas. [...] Percebi nesse período de PIBID na escola que houve melhoria no rendimento e nas notas dos alunos [...].

O relato da diretora nos ajudou a compreender um pouco mais sobre os objetivos do PIBID e do "Mais Educação" na escola. A partir da sua visão enquanto gestora, Denise consegue perceber a relevância de manter o contato e fazer crescer a relação entre faculdade e escola. Através do relato da diretora podemos confirmar a ideia de Prado \& Soligo (2010): a narrativa produzida nos ajuda na compreensão daquilo que sua autora está fazendo (acolhendo universitários na escola em que atua) e do que pensa sobre isso (acredita que a ligação entre a FFP e o Colégio Estadual Capitão Oswaldo Ornellas deve ser cultivada). 


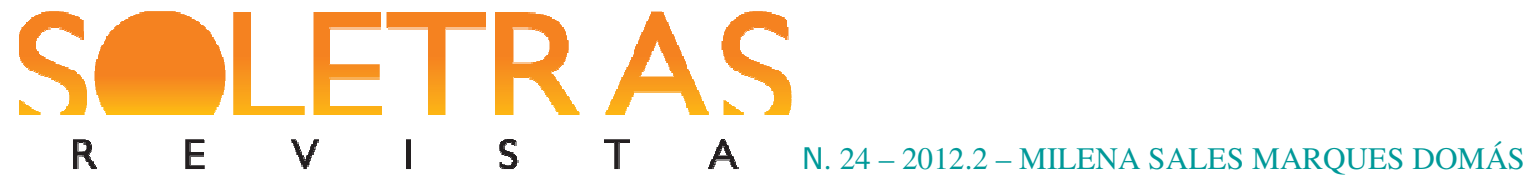

Após o contato com os relatos recolhidos, nos sentimos estimulados a registrar nossas impressões sobre a relação entre a Faculdade e a escola. Nesta parte do texto há um registro na primeira pessoa do singular, pois as ideias tratam de uma visão individual.

Minha primeira percepção das contribuições que a Faculdade poderia oferecer à escola se deu a partir de minha atuação como bolsista de Iniciação à docência e um pouco depois como estagiária. Assim como os bolsistas do PIBID e os monitores do "Mais Educação", fui estudante da FFP. Durante o período de graduação realizei algumas das atividades do projeto, bem como as exigências dos estágios supervisionados no Colégio Estadual Capitão Oswaldo Ornellas. Formei-me em 2010 pelo curso de Letras (Português/Literaturas) e, no mesmo ano, onde comecei a trabalhar? No "Oswaldo", como todos que lá trabalham costumam se referir à escola.

Enquanto bolsista e estagiária buscava contribuir com o trabalho já realizado na escola, levando atividades que fossem capazes de atrair alunos e estimular professores. Hoje, como docente da escola, meu olhar parte de outro lugar, de onde posso ver a contribuição de outros universitários para a escola e, principalmente, para o aprendizado dos alunos.

Consigo perceber como a dinâmica da escola muda com a chegada dos bolsistas, estagiários e monitores, vejo alunos que passam o dia inteiro no ambiente escolar para participar das aulas de canto, dança e teatro lecionadas por estudantes da FFP, monitores do projeto “Mais Educação”. Também vejo alunos ansiosos pela chegada dos bolsistas do PIBID, ansiosos para começar as leituras e as produções, ansiosos para ver essas produções expostas e valorizadas. Vejo ainda alunos dispostos a contribuir para que tudo dê certo nas atividades de estagiários. Percebo cada vez mais, e acredito não ser a única professora da escola a perceber isso, que a presença dos universitários na escola permite o desenvolvimento de atividades que, muitas vezes, nós, docentes, não conseguimos realizar no dia a dia da escola, em meio à correria do ano letivo, à necessidade de transmitir todo o conteúdo exigido pela grade curricular, "Currículo Mínimo”, Saerj etc.

Lembro-me com alegria do Festival de Poesias realizado pelos bolsistas e professores que fazem parte do PIBID. Foi o primeiro festival de poemas da escola! Tive a honra de ser escolhida como jurada e a felicidade de ver alunos meus como autores de ótimos poemas, outros, declamando muito bem e ainda outros empolgados na torcida por seus colegas.

Momentos como esse confirmam para mim o quanto é importante a ligação entre a Faculdade e a escola e entre a escola e a Faculdade, pois creio que esta também tem 


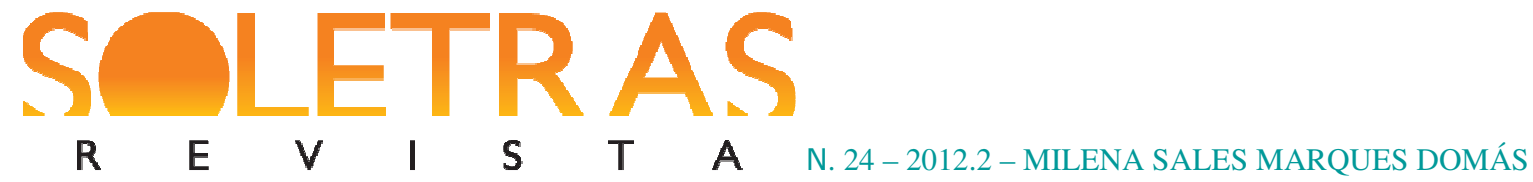

ganhado muito. A escola ganha, a faculdade ganha, os estudantes da escola e da faculdade ganham, eu e todos os professores que estão em contato com todo esse movimento ganhamos ao descobrir com nossos futuros colegas de trabalho, hoje bolsistas, estagiários e monitores, que a diversidade de caminhos para atrair nossos alunos é possível e válida.

\section{Que benefícios a escola e a Faculdade podem ver quando pontes são construídas?}

Nossas impressões e os relatos de experiência dos sujeitos que contribuíram para a configuração deste artigo nos permitiram identificar que quando pontes são construídas entre Faculdade e escola, as duas instituições de ensino são beneficiadas.

"A presença da universidade na escola é sinônimo de inovações, novas práticas" (relato de Maria José). "Um dos motivos para essa transformação é a forma como os bolsistas trabalham os conteúdos, com uma nova abordagem e usando vários recursos que muitos professores da escola na utilizam, como o Datashow." (relato de Dayse). "a proposta do PIBID é a de ter aulas diferenciadas daquelas do 'currículo normal' [...] Nós sempre tentamos usar todos os dispositivos disponíveis para atrair os estudantes." (relato de Eduardo). "Depois que comecei a participar dos projetos, meu desempenho como aluno melhorou, eles ajudam na minha formação e aprendo além do que normalmente aprendo na escola." (relato de Luan). "O PIBID trabalha com as turmas de maneira diferenciada. Os bolsistas desenvolvem o conteúdo de Português com aulas atrativas." (relato de Denise). Destacamos esses trechos dos relatos porque neles aparece um benefício em comum, todos tratam do desenvolvimento de atividades diferenciadas, do caráter da novidade. Com a presença dos projetos implementados por universitários na escola, é dada aos alunos a possibilidade de estar em contato com tarefas que nem sempre os professores conseguem propor no dia a dia da escola e usando, muitas vezes, recursos tecnológicos que não são utilizados normalmente.

Outro benefício que podemos listar do que apareceu nos relatos é a criação de laços que ocorrem entre alunos da escola e universitários. É muito importante propiciar condições aos educandos, em suas relações entre eles e/ou com os professores (e também com os futuros professores que já fazem parte da escola), de ensaiar a experiência, de assumir-se como uma pessoa social e histórica, que pensa, se comunica, tem sonhos, que tem raiva e que ama. (FREIRE, 2003). Alguns relatos mostram como a relação entre alunos da escola e universitários é importante para a formação de ambos; Camila cita um exemplo de um aluno que a partir da convivência com ela no projeto melhorou seu comportamento, deixando de ser 


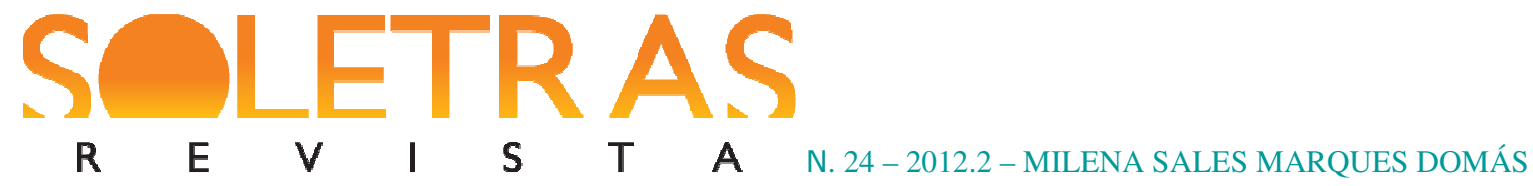

um aluno com problemas de relacionamento. Para os universitários, percebemos que a contribuição refere-se à experiência de estar em contato com alunos mesmo antes de terminar a graduação.

Como afirma Freire (2003, p. 23), "não há docência sem discência, as duas se explicam e seus sujeitos apesar das diferenças que os conotam não se reduzem a condição de objeto, um do outro. Quem ensina aprende ao ensinar e quem aprende ensina ao aprender". Vemos que há uma ligação entre os alunos da escola e os bolsistas, monitores e estagiários da FFP; como podemos perceber através dos relatos, os universitários já compreenderam que ensinam aos alunos da escola, mas também aprendem muito com eles.

É possível observar ainda um benefício que se refere ao anterior: a partir da atuação como bolsistas, monitores ou estagiários, os universitários estão sendo preparados para estarem futuramente em sala de aula como professores; além disso, têm a oportunidade de saber se realmente desejam seguir a profissão. De acordo com Nóvoa, "é evidente que a Universidade tem um papel importante a desempenhar na formação de professores. [...] Mas a bagagem essencial de um professor adquire-se na escola." (2003, p. 5). Acreditamos que os bolsistas do projeto PIBID e monitores do "Mais Educação" têm adquirido essa bagagem, é o que o bolsista Eduardo traduz bem em seu relato: "Foi a partir de minha participação no PIBID que tive meu primeiro contato com uma escola sem estar na posição de aluno; esse contato, a experiência efetiva com uma metodologia de ensino, o contato com as novas tecnologias, a promoção e a formulação do projeto me fizeram ter certeza da minha vocação como professor, certeza de que é realmente isso que eu quero. Creio que isso irá refletir quando eu estiver com um diploma na mão".

\section{Conclusão}

A configuração do artigo foi muito importante para que pudéssemos compreender com mais clareza a importância da "construção de pontes" entre Faculdade e escola, mais especificamente entre a FFP e o Colégio Estadual Capitão Oswaldo Ornellas. Por mais que estivéssemos três vezes por semana na escola, observando todo o movimento realizado pelos monitores, bolsistas e estagiários com os alunos e professores da escola, durante o período de escrita do presente trabalho, precisamos mudar o nosso olhar, estando mais atentos às mudanças que os projetos (PIBID, "Mais Educação", projetos realizados por estagiários) têm gerado na vida da escola. 


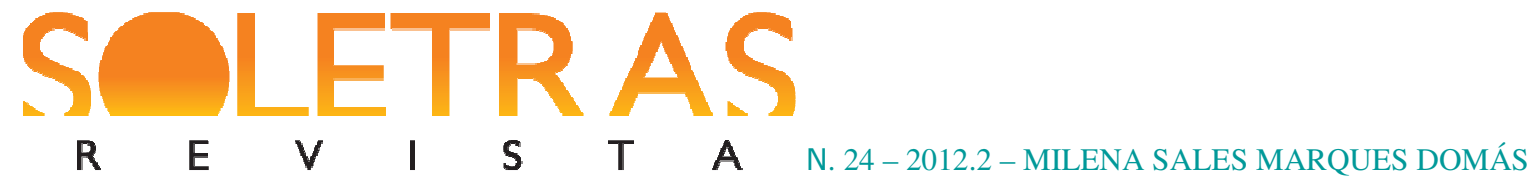

Retomando o nosso relato acima, percebemos "o quanto é importante a ligação entre a faculdade e a escola e entre a escola e a faculdade [...]. A escola ganha, a faculdade ganha, os estudantes da escola e da faculdade ganham, [...] todos os professores que estão em contato com todo esse movimento ganham ao descobrir com futuros colegas de trabalho, hoje bolsistas, estagiários e monitores, que a diversidade de caminhos para atrair nossos alunos é possível e válida.”.

Além disso, descobrimos a relevância de valorizar as vozes, as opiniões, as impressões de sujeitos que estão envolvidos nessa relação entre a faculdade e a escola; foram os seus relatos que nos ajudaram a compor este artigo, identificando mudanças ocorridas no ambiente escolar e benefícios dos quais indivíduos da FFP e do Colégio Estadual Capitão Oswaldo Ornellas podem desfrutar dessa ligação.

\title{
Referências bibliográficas:
}

FREIRE, P. Pedagogia da autonomia: saberes necessários à prática educativa. São Paulo: Paz e Terra, 2003.

NÓVOA, A. Novas disposições dos professores: A escola como lugar da formação. Adaptação de uma conferência proferida no II Congresso de Educação do Marista de Salvador (Bahia, Brasil), em julho de 2003. Disponível em:<http://repositorio.ul.pt/bitstream/10451/685/1/21205_ce.pdf.>. Acesso em dezembro de 2011.

PRADO, G. do V.; SOLIGO, R. Memorial de Formação: quando as memórias narram a história de formação. <http://www.fe.unicamp.br/ensino/graduação/downloads/proesfmemori Al_GuilhermePrado_RosauraSoligo.pdf.>. Acesso em outubro de 2011.

\section{College students go to school: reports of subjects involved in "building bridges" between the School of Teacher Education (Faculdade de Formação de Professores -FFP) and the State College of UERJ Captain Oswaldo Ornellas}

\begin{abstract}
The object of this research is to analyze the relationship between College and School. Its purpose is to reflect, specifically, about the changes occurred in the State School Captain Oswaldo Ornellas, in São Gonçalo, based on the actions carried out by the fellows of the Institutional Scholarship Program Initiation to Teaching (Programa Institucional de Bolsa de Iniciação à Docência, PIBID) along with the activities developed by monitors from the project "Mais Educação", who are graduate students from the Faculdade de Formação de Professores (FFP/UERJ). We collected reports from students and professionals involved with UERJ's FFP and the School unit in question. The subjects whose experiences are reported in
\end{abstract}


$\begin{array}{llllllll}\mathbf{R} & \mathbf{E} & \boldsymbol{V} & \mathbf{I} & \mathbf{S} & \mathbf{T} & \mathbf{A} & \text { N. 24-2012.2-MILENA SALES MARQUES DOMÁS }\end{array}$

this paper are: (1) teachers / supervisors of Pibid; (2) a Fellow of the same project; (3) a monitor of the Project "Mais Educação"; (4) a student of the referred school; (5) and the General Director of the School Unit. We believe that the relevance of this research consists in evaluating what the benefits generated to students, teachers and future teachers at the moment bridges are built between College and Schools.

Keywords: College. School. Reports of experiences. Training.

Recebido em: 15 de dezembro de 2012.

Aprovado em: 12 de janeiro de 2012. 